Association for Information Systems AIS Electronic Library (AISeL)

December 2002

\title{
RESEARCH ON PROCESS STRUCTURE FOR DISTRIBUTED, ASYNCHRONOUS COLLABORATIVE WRITING GROUPS
}

Paul Lowry

Brigham Young University

Follow this and additional works at: http://aisel.aisnet.org/amcis2002

\section{Recommended Citation}

Lowry, Paul, "RESEARCH ON PROCESS STRUCTURE FOR DISTRIBUTED, ASYNCHRONOUS COLLABORATIVE WRITING GROUPS" (2002). AMCIS 2002 Proceedings. 297.

http://aisel.aisnet.org/amcis2002/297 


\title{
RESEARCH ON Process STRUCTURE FOR Distributed, ASYNCHRONOUS COLLABORATIVE Writing GROUPS
}

\author{
Paul Benjamin Lowry \\ Brigham Young University \\ Marriott School of Management \\ Paul.Lowry@BYU.Net
}

\begin{abstract}
This paper investigates using higher levels of scripted process structure (procedural explicitness) to improve outcomes of distributed, asynchronous collaborative writing $(\mathrm{CW})$ teams that work on the Internet. This paper reports preliminary results of a one-and-a-halfmonth field experiment on asynchronous collaborative writing using 550 participants. It is found that the highest levels of process structure provide the most benefits to the examined distributed work teams, which has important implications for optimizing distributed group work.
\end{abstract}

\section{Introduction}

This paper presents how variations in process structure or procedural explicitness have significant impact on distributed collaborative writing (CW), a key form of distributed work. The basic research question that is addressed is whether increased procedural explicitness has a benefit to distributed work groups, as opposed to letting distributed groups work "naturally." However, before proceeding with the details of this research, this section emphasizes the growing importance of distributed CW.

$\mathrm{CW}$ is a critical form of professional communication that can be more effective than single-author writing (Gere \& Abbott, 1985) and is ubiquitously performed in industry and academia (Couture \& Rymer, 1989; Ede \& Lunsford, 1990; Gordon, 1980). Moreover, while $\mathrm{CW}$ is already pivotal to many group processes, it is likely to increase in importance and complexity because of the increased use of distributed work, driven by increased globalization, competition, and Internet usage. Since CW is a significant form of group work, as distributed group work increases, distributed CW will also likely increase in usage. By 1998, over $17 \%$ of industry meetings involved remote participants (Simons, 1998), and it is likely to increase in prevalence over time (Burke \& Chidambaram, 1994).

Two key reasons exist why distributed work will continue to increase and thus drive an increase in CW work: (1) increased globalization and competition (2) increased Internet usage.

Increased globalization: The globalization of business has been said to require the innovative pressure to support collaboration regardless of time and place (Hax \& Majluf, 1991; Horton, Holman, \& Bess, 1992; Johansen et al., 1991). Similarly, "Today's complex organizational problems transcend functional staff boundaries and single site proximities" (Horton et al., 1992) p. 1. Moreover, changing dynamics in the workplace where work teams are primarily engaged in "intellectual teamwork" (Galegher \& Kraut, 1990) increase the need to support distributed intellectual work. Other reasons globalization increases the use of distributed work include (Herbsleb, Mockus, Finholt, \& Grinter, 2000):

(1) The increased use of mergers and acquisitions causes firms to have more physical sites;

(2) Many governments require local development operations before a firm can enter an international market;

(3) Firms increasingly locate operations where a market exists;

(4) High competition for talent requires firms to locate where employees live and/or to use remote workers;

(5) Many firms strive for a distributed work force in order to achieve 24-7 production and/or development. 
Increased Internet usage: The Internet has also increased demand for distributed work. This phenomena's effect on business work is aptly described as "Continuous, wild change at breakneck speed; new, newer, and newest technology; globalization and localization; and a demand for social as well as financial performance all typify business in the Internet Age" (Lipnack \& Stamps, 2000) p. 1. Several reasons exist for the increased use of the Internet for distributed work: For example, the Internet is virtually ubiquitous; it is available in most countries 24 hours a day. Additionally, Internet access is inexpensive and easy for even poorly trained users to secure access. Furthermore, the Internet promulgates communication and networking standards that are widely accepted in the International community, which collectively has made the Internet the de facto distributed work medium, creating strong network externalities: Since so many people and organizations use the Internet, every businessperson and academician must participate in some form or face losing the opportunities it affords. Clearly, "As more people interconnect online, we increase our capacity for both independence and interdependence" (Lipnack \& Stamps, 2000) p. xxiv. As a result, the global economy fueled by the Internet has increased the pace and need for knowledge production and the need for employees to augment their ability to "enhance, shape and focus corporate intelligence" (Mandel, 1999).

Finally, the increasing use of distributed work, especially over the Internet, has transformed many traditional F2F (face-to-face) meetings into virtual meetings, which can ideally be: "productive, interactive frameworks, where people actively engage in structured conversational applications focused on organizational learning, virtual teaming, strategic development, and all other activities aimed at increasing the collective intelligence of the company - the shared knowledge and understandings that drive effective action" (Mandel, 1999) p. 2.

Given that CW is an important form of group work that is increasingly conducted in tele- or distributed settings, the rest of this paper investigates using variations in scripted process structure to improve outcomes of distributed, asynchronous collaborative writing $(\mathrm{CW})$ teams that work on the Internet. First, this paper explores the theoretical implications of process structure in asynchronous, distributed $\mathrm{CW}$. The resulting hypotheses are tested using a field experiment of 550 participants using a Java-based CW tool called, Collaboratus, a Java-based, distributed CW tool further explained in (Lowry, 2002; Lowry, Albrecht, Nunamaker Jr., \& Lee, 2002). The results of the field experiment with corresponding contributions, limitations, and future research opportunities are then presented.

\section{Process Structure and Explicitness in Distributed Work}

This section proposes hypotheses to test the effects of varying different levels of process structure in CW scripts, for the various distributed $\mathrm{CW}$ outcomes. Research has shown that groups that follow structured procedures tend to outperform groups following their natural group interaction without structure (Miner, 1979). Conversely, unstructured groups tend to come to premature decisions that are suboptimal because they do not consider all the relevant angles of a problem (Maier \& Hoffman, 1960). Additionally, increased process structure can result in more effective and efficient group communication (Chilberg, 1989). Likewise, process interventions have been shown to help raise decision quality and process satisfaction (Lee-Partridge, 1992). In addition, research has shown that non-cohesive groups can benefit from structured management, involving breaking large tasks into small components (Kiesler \& Cummings, 2001). Moreover, field observations of CW groups using GSS for CW led to the conclusion that appropriate structured processes are vital to successful CW outcomes (Nunamaker Jr., Briggs, Mittleman, Vogel, \& Balthazard, 1997). Likewise, case studies in CW led to the conclusion that structured processes improve outcomes in synchronous, distributed sessions (Sasse \& Handley, 1996). Similarly, a case study involving advanced graduate students found groups following structured procedures outperformed those without structured procedures (Barnum, 1994).

Increased process structure has other important benefits, including promotion of the use of appropriate sequential processes in groups, which can lead to increased clarity and improved idea development (Brashers, Adkins, \& Meyers, 1994). Moreover, research has shown that procedure knowledge is more difficult for novices to assimilate than declarative knowledge and usually is only gained after declarative knowledge is gained (Vessey \& Conger, 1993). Thus, process interventions have the potential to help novices and first-time group members by lessoning the cognitive load required to learn appropriate processes and tasks. This remainder of this section proposes hypotheses to test the effects of varying different levels of process structure in CW scripts, for the following outcomes: productivity, quality, satisfaction, relationships, and communication.

\section{Literature on the Effects of Process Structure on Productivity}

Research has shown that moderate levels of structure provide better results than no or poor structure, while too much structure also provides worse results than moderate structure (Van de Ven \& Delbecq, 1974; White, Dittrich, \& Lang, 1980). It may be 
reasonable to suppose that implementation of increased process structure will increase the probability of even participation in a $\mathrm{CW}$ group, which can increase a group's output quantity. For example, researchers found that interactive GSS groups generated a greater number of unique ideas than non-interactive groups (Easton, Vogel, \& Nunamaker Jr., 1992; Jessup, Egbert, \& Connolly, 1996). Similarly, interactive GSS groups can have more even participation than non-interactive groups (Easton, Vogel, \& Nunamaker Jr., 1989), while structured approaches, whether manual or computerized, can exhibit greater equality of participation in CW groups (Easton, 1988).

\section{Literature on the Effects of Process Structure on Quality}

Group research indicates that improved process structure through use of advanced collaborative tools and/or process interventions can improve the quality of group results. For example, research indicates that unstructured groups tend to come to premature decisions that are suboptimal because they do not consider all the relevant angles of a problem (Maier \& Hoffman, 1960). Moreover, including planning and structure in non-technology groups tends to improve overall outcomes, especially for larger groups (Shay, 1981). Likewise, groups that are given decomposed tasks with standard procedures tend to be more autonomous in their decisions, which improves their role clarity and innovativeness (Johnson, La France, Meyer, Speyer, \& Cox, 1998), both of which can increase quality.

In terms of CW tool research, structured approaches, whether manual or computerized, have led to better quality outcomes in CW groups, than unstructured groups (Easton, 1988). Likewise, quality of planning has been shown to be related to document quality (Carey, Flower, Hayes, Schriver, \& Haas, 1989); although, this was not verified by (Easton, Eickelmann, \& Flatley, 1994).

\section{Literature on the Effects of Process Structure on Satisfaction}

Low structure GSS groups can have less satisfaction than low structure non-GSS groups (McLeod \& Liker, 1992). This finding is pivotal because although both groups were given low structure processes, GSS technology inherently provides more process structure; hence, the increased structure from GSS use may relate to increased satisfaction. More conclusively, both in CW (Easton, 1988) and group research (Easton et al., 1989) structured approaches in groups, whether manual or computerized, have produced higher levels of decision and process satisfaction than groups that lack structure. Recent research showed that using parallel coordination in conjunction with a group leader led to higher process satisfaction than using sequential process coordination (Kim, Hiltz, \& Turoff, 1998). While the research tying satisfaction to low and high levels of structure is clearly mixed, it may be reasonable to assume that groups with no structure will have a higher probability of experiencing less satisfaction than groups that have some structure, on the assumption that most groups desire some process guidance. For example, several field studies suggest that tasks that are more complex need more structured facilitation to achieve success (Nunamaker Jr. et al., 1989; Van de Ven \& Delbecq, 1974; White et al., 1980).

\section{Literature on the Effects of Process Structure on Relationships}

Some of the potential benefits of increased structure include a more even distribution of participation, which can lead to an increase in consensuses. For example, structured approaches, whether manual or computerized, promote greater equality of participation than unstructured approaches (Easton, 1988). Additionally, structured GSS groups can have more even distribution of participation than unstructured groups (Easton et al., 1989). Furthermore, interactive GSS groups can have more even participation than non-interactive groups (Easton et al., 1992). Even though increased participation does not necessarily translate directly into consensus, it does decrease the probability that an individual will dominate a group's processes, increasing the probability of consensus occurring. Meanwhile, groups achieving consensus are more likely to have good relationships than groups experiencing domination or discord. For example, research revealed that chauffeur-driven groups (higher structure) achieved significantly higher post-meeting consensus than did facilitator-driven groups (lower structure) (Dickson, Lee, Robinson, \& Heath, 1989). Clearly, the processes and tasks a group chooses affects all kinds of outcomes such as agenda creation, turn taking in communication, how decisions are made, and underlying agreement (Davis, 1992). For example, in free discussions different outcomes occur depending on the order in which group members discuss issues and the routine procedures they employ such as straw polling (Davis, 1992).

Despite the potential relationship advantages of increased structure, research also suggests that "too much" structure can also undermine relationships, especially in terms of consensus and cohesion. For example, Dickson (Dickson, Lee-Partridge, \& 
Robinson, 1993) concluded that highly structured, rigid facilitation decreases consensus. Likewise, Anson (Anson, Bostrom, \& Wynne, 1995) found that flexible facilitation improves group cohesion as opposed to highly structured facilitation (Anson et al., 1995).

\section{Literature on the Effects of Process Structure on Communication}

This research posits that just as with consensus, the structure employed by a group should have a direct impact on its communication practices. Communication in $\mathrm{CW}$ groups is crucial because $\mathrm{CW}$ is an open-ended problem centering on highly expressive and interactive communication (Galegher \& Kraut, 1994). It was previously stated that increased structure should increase participation and interaction (Easton, 1988); likewise, higher structure groups should be more likely to have better communication than lower structure groups, because of their increased participation and interactivity. Furthermore, a logical upper limit on structure exists with communication, where extremely high levels of structure should naturally decrease a group's communication, since such levels of structure would undermine their need to make and discuss decisions (Galegher \& Kraut, 1994). In summary, the following hypothesis derives from this section:

H1: Small, asynchronous, distributed CW groups that use Collaboratus and have no imposed process structure will have worse results than similar groups with low or high process structure, while low structured groups will have the best results; all in terms of (a) productivity, (b) quality, (c) satisfaction, (d) relationships, and (e) communication.

\section{Methods: Testing Process Structure in Distributed CW Groups}

This section describes an experiment that was conducted to test small distributed, asynchronous CW groups using Collaboratus with different process scripts, to help establish which processes and scripts are the most effective for non-facilitator-lead CW teams. This field experiment was conducted over a month and a half, involving 550 participants who were required to participate for a substantial portion of their course grade. As such, this field experiment sacrificed control for the sake of realism / external validity. Approximately 550 students were enrolled in the three sections and started the project, while 479 students completed the project. Meanwhile, 47 students started the project but did not fully complete it for various reasons.

\section{Research Design}

The general research design for this experiment was a one-way ANOVA, where the "A" factor represented the level of structure a group used for its CW process: no structure, low structure, or high structure.

\section{Research Procedures}

This research was limited to small, distributed work groups. No other work modes or group sizes were tested. Furthermore, this research focused on the activities of group formation, planning, brainstorming, drafting, reviewing, and revising activities of collaborative writing. Hence, the primary Collaboratus features that were used included the following: group outliner, group interface, editing, and locking. In all treatments, subjects were given exact scripts and directions on how to proceed. All subjects conducted their communication via Nicenet's ${ }^{\mathrm{TM}}$ asynchronous chat facility and email; all $\mathrm{CW}$ was conducted using Collaboratus.

Participants were given basic instructions via email for the particular activity they were supposed to be engaged in. As time productivity was a key dependent variable, no set time limits were given for each session; although, all participants were given general suggestions and guidelines on time and length in several conditions. Thus, groups were allowed to progress at their own pace.

All groups worked toward the same writing task, which was essentially to come up with several problems that exist at the UofA that negatively affect undergraduates and to come up with creative and feasible solutions. Additionally, all participants were given a general schedule and deadline as to when the six assignments for the writing experiments needed to be completed. Finally, participants completed three, questionnaires to assist data collection. 


\section{Research Results}

It was determined that most of the measures involved in the experiment are highly interdependent group data. As a result, virtually all the data was analyzed using regressions that factor out the effects of intracorrelations, as advocated by (Kashy \& Kenny, 2000). Thus, all F-test results reflect these adjustments, with the exceptions of "document length" and "chat length," which were group-level data that were not intracorrelated. Table 1 shows significant results related to the structure control variable. ${ }^{1}$

Table 1. Significant Results for Structure Control Variable

\begin{tabular}{|c|c|c|c|c|c|c|}
\hline Hypothesis & $\begin{array}{l}\text { Directional } \\
\text { Comparison }\end{array}$ & Variable & Struc 0 & Struc 1 & Struc 2 & Adjusted F statistic \\
\hline H1a & s: 1 vs. 3 & Document length & 1698.76 & $\mathrm{n} / \mathrm{a}$ & 2493.09 & $8.14 *$ \\
\hline H1a & s: 1 vs. 2 & Chat length & 317.39 & 665.62 & $\mathrm{n} / \mathrm{a}$ & $5.53 *$ \\
\hline H1a & s: 1 vs. 3 & Chat length & 317.39 & $\mathrm{n} / \mathrm{a}$ & 780.23 & $9.03 *$ \\
\hline H1a & s: 1 vs. 2 & Time spent group formation & 37.40 & 30.72 & $\mathrm{n} / \mathrm{a}$ & $2.70+$ \\
\hline $\mathrm{H} 1 \mathrm{a}$ & s: 1 vs. 2 & Time spent brainstorming & 40.97 & 33.81 & $\mathrm{n} / \mathrm{a}$ & $3.73 *$ \\
\hline H1a & s: 1 vs. 3 & Time spent outlining & 31.67 & $\mathrm{n} / \mathrm{a}$ & 41.02 & $5.71 *$ \\
\hline H1a & s: 1 vs. 2 & Time spent drafting & 91.67 & 67.31 & $\mathrm{n} / \mathrm{a}$ & $8.60 *$ \\
\hline $\mathrm{H} 1 \mathrm{~b}$ & s: 1 vs. 3 & Externally judged quality & 4.20 & $\mathrm{n} / \mathrm{a}$ & 4.67 & $3.12+$ \\
\hline $\mathrm{H} 1 \mathrm{~b}$ & s: 1 vs. 3 & Quality of process / discussion & 4.78 & $\mathrm{n} / \mathrm{a}$ & 5.22 & $5.78 *$ \\
\hline $\mathrm{H} 1 \mathrm{c}$ & s: 1 vs. 3 & Satisfaction with process & 4.77 & $\mathrm{n} / \mathrm{a}$ & 5.27 & $5.17 *$ \\
\hline H1d & s: 1 vs. 3 & Evaluation & 3.98 & $\mathrm{n} / \mathrm{a}$ & 4.23 & $6.45^{*}$ \\
\hline H1d & s: 1 vs. 2 & Teamwork & 4.96 & 5.19 & $\mathrm{n} / \mathrm{a}$ & $2.71+$ \\
\hline $1 \mathrm{~d}$ & s: 1 vs. 3 & Teamwork & 4.96 & $\mathrm{n} / \mathrm{a}$ & 5.27 & $4.90 *$ \\
\hline H1d & s: 1 vs. 3 & Appropriateness & 5.21 & $\mathrm{n} / \mathrm{a}$ & 5.63 & $5.63 *$ \\
\hline H1d & s: 1 vs. 3 & Involvement & 4.67 & $\mathrm{n} / \mathrm{a}$ & 5.02 & $3.26+$ \\
\hline H1e & s: 1 vs. 3 & $\begin{array}{l}\text { Task orientation of } \\
\text { communication }\end{array}$ & 4.61 & $\mathrm{n} / \mathrm{a}$ & 4.99 & $3.91 *$ \\
\hline H1e & s: 1 vs. 3 & Richness of communication & 4.42 & $\mathrm{n} / \mathrm{a}$ & 4.75 & $3.48+$ \\
\hline
\end{tabular}

$*$ significant at both $\alpha=.05$ and $\alpha=.10+=$ significant only at $\alpha=.10$

Struc 0 = no structure condition; Struc 1 = low structure condition; Struc 2 = high structure condition

Overall, in partial contradiction to the literature, groups with increased structure were much more productive than groups with no structure, which was in partial contradiction of the hypotheses that predicted medium structure groups having the most optimal outcomes. For example, "high-structure" groups produced significantly longer document lengths than "no-structure" groups. Likewise, chat lengths of "low" and "high-structure" groups were much higher than "no-structure" groups. In terms of time, "high-structure" groups were more efficient when outlining than "no-structure" groups and "low-structure" groups were more efficient than "no-structure" groups in terms of group formation, brainstorming, and drafting. No other time differences were significant. "High-structure" groups also had more satisfaction, perceived quality, and externally judged quality than "nostructure" groups. "Low-structure" groups did not record any significant over "no-structure" groups in these areas. In terms of relationships, "high-structure" groups also outperformed "no-structure" groups, as measured by evaluation, appropriateness, teamwork, and involvement. "Low-structure" groups only outperformed "no-structure" groups concerning teamwork. Finally, "high-structure" groups outperformed "no-structure" groups in terms of task discussion and communication richness.

${ }^{1}$ Doclen and chatlen tested at $\mathrm{F}(1,150)_{\alpha=.05}$ where $\mathrm{F}_{\text {crit }}=3.9042$; all other measures were tested at $\mathrm{F}(1,432) \mathrm{\alpha}^{=.05}$ where $\mathrm{F}_{\text {crit }}=3.84$ and $\mathrm{F}(1,432) \alpha_{\alpha=10}$ where $\mathrm{F}_{\text {crit }}=2.71$. Note that all structure-related hypotheses involved direct comparisons. 
In summary, "no-structure" groups did not exhibit better outcomes over "low-structure" and "high-structure" groups in any area. Meanwhile, "low-structure" groups exhibited some benefits over "high-structure" groups, while "high-structure" groups exhibited many benefits over "low-structure" groups. Thus, it appears for the experimental conditions given that "high-structure" groups provided most optimal results.

\section{Discussion}

This final section of the paper discusses overall findings, contributions, limitations; and proposes future research in the study of process structure / procedural explicitness in distributed work groups.

\section{Contributions and Findings}

In terms of implications to distribute work groups, it appears that distributed work groups (at least those in the aforementioned conditions) significantly benefit from high level of process structure, or procedural explicitness. This implies that advanced GSS or CMC tools alone will not help distributed groups work in their most effective manner; instead, the combination of technology and structured processes is the most beneficial for distributed groups. This also implies that a significant amount of work needs to be conducted to establish appropriate processes for certain kinds of distributed work groups. In other words, giving a distributed work group a highly structured tool without explicit procedures (e.g. letting them work "naturally") will likely cause suboptimal results.

\section{Limitations}

One of the biggest limitations of this experiment could also be said to be one of its greatest strengths - that this was a field experiment conducted on a 24 hour, 7 day a week basis. As a result, significant amounts of control were given up in trade off for increased realism, which resulted in students using different forms of equipment, in different locations, at different times. Furthermore, while all chat discussions and collaborative work were logged, groups could not be strictly forced to follow their instructions. Where groups violated experiment rules and instructions they were dropped from the experiment; yet, it is likely some non-compliant group data may still exist in the data set.

Another limitation of the overall findings is that the participants were $\mathrm{CW}$ novices with no established working history. Thus, it may be that high structure was positive because such students and conditions need more structure. While this should not undermine the importance of the findings for the given experimental conditions, the findings may not be very generalizable to other tasks. Although, a previous case study using advanced graduate students with extensive CW experience still found that students given more process structure outperformed those with less structure (Barnum, 1994).

An additional limitation of this experiment is that it focused solely on enhanced processes in conjunction with Collaboratus. It is likely that these processes could also be beneficial to non-Collaboratus technologies - or even more beneficial. Thus, it may have been useful to use Word ${ }^{\mathrm{TM}}$ groups as a control.

\section{Future Research}

One useful area of inquiry in process research would be to investigate the upper limits of process structure in distributed work groups (e.g. where it is considered detrimental). It would also be insightful to test variations of automation of high-process structure scripts; for example, to ascertain the differences attributed to the use of an agent, a facilitator, and a typewritten script for the same process.

Additional process-related research should likely be conducted for specific CW tasks, on the basis that highly task-specific CW may need process modifications to achieve optimal results. Examples of highly task-specific CW that likely have different process needs include strategy documents, group creative writing, academic articles, corporate strategy documents, policy and procedure manuals, proposals, and edited books with many contributors. The basis for this general claim is that some writing tasks are complex (e.g. strategy documents and academic journal articles), while some are simple (e.g. meeting notes); thus, some writing tasks involve large numbers of stakeholders (e.g. strategy documents) and complex processes, while other writing tasks involve 
few people (e.g. academic term papers) and have simple processes. Likewise, it is likely that complex tasks need more process support than less complex tasks. However, because of the lack of literature and theory support, task-specific process suggestions at this point are highly exploratory. It would also be useful to parcel out the ideal high-structure CW processes to determine which suggested activities and tasks are responsible for positive outcomes and which are detrimental. Finally, it would be highly useful to try to replicate these findings on the benefits of high process structure to other forms of distributed group work, other than $\mathrm{CW}$.

\section{References}

Anson, R., Bostrom, R. P., \& Wynne, B. E. (1995). An experiment assessing group support system and facilitator effects on meeting outcomes. Management Science, 41(2), 189-208.

Barnum, C. M. (1994). Collaborative writing in graduate technical communication - is there a difference. Journal of Technical Writing and Communication, 24(4), 405-419.

Brashers, D. E., Adkins, M., \& Meyers, R. A. (1994). Argumentation and computer-mediated group decision making. In L. R. Frey (Ed.), Group Communication in Context: Studies of Natural Groups . Hillsdale, NJ: Lawrence Erlbaum Associates.

Burke, K., \& Chidambaram, L. (1994). Development in electronically-supported groups: A preliminary longitudinal study of distributed and face-to-face meetings. Paper presented at the Twenty-Seventh Hawaii International Conference on Systems Sciences, Maui, Hawaii.

Carey, L., Flower, L., Hayes, J. R., Schriver, K. A., \& Haas, C. (1989). Differences in writers' initial task representations (Technical Report 35). Pittsburgh: Center for the Study of Writing, University of California at Berkeley and Carnegie Mellon University.

Chilberg, J. C. (1989). A review of group process designs for facilitating communication in problem-solving groups. Management Communication Quarterly, 3(1), 51-71.

Couture, B., \& Rymer, J. (Eds.). (1989). Interactive Writing on the Job: Definitions and Implications of Collaboration. Urbana, IL: NCTE and ABC.

Davis, J. H. (1992). Some compelling intuitions about group consensus decisions, theoretical and empirical research, and interpersonal aggregation phenomena: Selected examples, 1950-1990. Organizational Behavior and Human Decisions Processes, 52, 3-38.

Dickson, G. W., Lee, J. E., Robinson, L., \& Heath, R. (1989, January 3-6). Observations on GDSS interactions: Chauffeured, facilitated, and user-driven systems. Paper presented at the Twenty-Second Hawaii International Conferences on System Sciences, Kailua-Kona, Hawaii.

Dickson, G. W., Lee-Partridge, J. E., \& Robinson, L. H. (1993). Exploring modes of facilitative support for GDSS technology. MIS Quarterly, 17(2), 173-194.

Easton, A. (1988). An experimental investigation of automated versus manual support for stakeholder identification and assumption surfacing in small groups (unpublished doctoral dissertation ). Tucson, Arizona: University of Arizona.

Easton, A. C., Eickelmann, N. S., \& Flatley, M. E. (1994). Effects of an electronic meeting system group writing tool on the quality of written documents. Journal of Business Communication, 31(1), 27-40.

Easton, A. C., Vogel, D. R., \& Nunamaker Jr., J. F. (1989). Stakeholder identification and assumption surfacing in small groups: An experimental study. Paper presented at the Twenty-Second Annual Hawaii International Conference on System Sciences, Kailua-Kona, Hawaii.

Easton, A. C., Vogel, D. R., \& Nunamaker Jr., J. F. (1992). Interactive versus stand-alone group decision support systems for stakeholder identification and assumption surfacing in small groups. Decision Support Systems, 8, 159-168.

Ede, L., \& Lunsford, A. (1990). Singular texts/plural authors: Perspectives on collaborative writing. Carbondale, IL: Southern Illinois University Press.

Galegher, J., \& Kraut, R. E. (1990). Computer-mediated communication for intellectual teamwork: a field experiment in group writing. Paper presented at the Conference on Computer-Supported Cooperative Work, Los Angeles, CA.

Galegher, J., \& Kraut, R. E. (1994). Computer-mediated communication for intellectual teamwork: An experiment in group writing. Information Systems Research, 5(2), 110-138.

Gere, A. R., \& Abbott, R. D. (1985). Talking about writing: The language of writing groups. Research in the Teaching of English, $19(4), 362-385$.

Gordon, M. D. (1980). A critical reassessment of inferred relations between multiple authorship, scientific collaboration, and the production of papers and their acceptance for publication. Scientometrics, 2, 193-201.

Hax, A. C., \& Majluf, N. S. (1991). The Strategy, Concept and Process: A Pragmatic Approach. Englewood Cliffs, NJ: PrenticeHall, Inc. 
Herbsleb, J. D., Mockus, A., Finholt, T. A., \& Grinter, R. E. (2000). Distance, dependencies, and delay in global collaboration. Paper presented at the Conference on Computer-Supported Cooperative Work, Philadelphia, PA.

Horton, M. S., Holman, R. A., \& Bess, D. A. (1992). Groupware enablers and business solutions. Paper presented at the IEEE International Conference on Systems, Man, and Cybernetics.

Jessup, L. M., Egbert, J. L., \& Connolly, T. (1996). Understanding computer-supported group work: The effects of interaction frequency on group process and outcome. Journal of Research on Computing in Education, 28(2), 190-208.

Johansen, R., Sibbet, D., Benson, S., Martin, A., Mittman, R., \& Saffo, P. (1991). Leading business teams: How teams can use technology and group process tools to enhance performance. Reading, MA: Addison-Wesley Publishing Company.

Johnson, J. D., La France, B. H., Meyer, M., Speyer, J. B., \& Cox, D. (1998). The impact of formalization, role conflict, role ambiguity, and communication quality on perceived organizational innovativeness in the cancer information service. Evaluation and the Health Professions, 21, 27-51.

Kashy, D. A., \& Kenny, D. A. (2000). The analysis of data from dyads and groups, Handbook of research methods in social and personality psychology (pp. 451-477). NY, NY: Cambridge University.

Kiesler, S., \& Cummings, J. N. (2001). What do we know about proximity and distance in work groups? In P. Hinds \& S. Kiesler (Eds.), Distributed Work . Cambridge, MA: MIT Press.

Kim, Y., Hiltz, S. R., \& Turoff, M. (1998). Coordination structures and systems restrictiveness in distributed group support systems: An experiment on coordination mode and leadership. Paper presented at the Thirty-first Hawaii International Conference on Systems Sciences, Big Island, Hawaii.

Lee-Partridge, J. E. (1992). An empirical investigation of task and interactional facilitator intervention in the use of group decision support systems (unpublished doctoral dissertation ). Minneapolis, MN: University of Minnesota.

Lipnack, J., \& Stamps, J. (2000). Virtual Teams: People Working Across Boundaries with Technology. NY, NY: John Wiley and Sons.

Lowry, P. B. (2002). Improving distributed collaborative writing on the Internet using enhanced processes and a Java-based collaborative writing tool (unpublished doctoral dissertation ). Tucson, Arizona: University of Arizona.

Lowry, P. B., Albrecht, C. C., Nunamaker Jr., J. F., \& Lee, J. D. (2002). Evolutionary development and research for an Internetbased Collaborative Writing tool to enhance eWriting in an eGovernment setting. Decision Support Systems, Accepted for publication in 2002.

Maier, N., \& Hoffman, L. (1960). Quality of first and second solutions in group-problem solving. Journal of Applied Psychology, 44(4), 310-323.

Mandel, T. (1999, May 26, 2001). How companies think: Creating collaborative intelligence online, [Internet]. Caucus. Available: http://www.caucus.com/pdf/howcompaniesthink.pdfMay 26, 2001].

McLeod, P. L., \& Liker, J. K. (1992). Electronic meeting systems: Evidence from a low structure environment. Information Systems Research, 3(3), 199-223.

Miner, F. C., Jr. (1979). A comparative analysis of three diverse group decision making approaches. Academy of Management Journal, 22(1), 81-93.

Nunamaker Jr., J. F., Briggs, R. O., Mittleman, D. D., Vogel, D. R., \& Balthazard, P. A. (1997). Lessons from a Dozen Years of Group Support Systems Research: A Discussion of Lab and Field Findings. Journal of Management Information Systems, 13(3), 163-207.

Nunamaker Jr., J. F., Vogel, D., Heminger, A., Martz, B., Grohowski, R., \& McGoff, C. (1989). Experiences at IBM with Group Support Systems. Decision Support Systems, 5(2), 183-196.

Sasse, M., \& Handley, M. (1996). Collaborative writing with synchronous and asynchronous support environments: Academic Press.

Shay, M. (1981). Group Dynamics: The Psychology of Small Group Behavior (Third ed.). NY, NY: McGraw-Hill.

Simons, M. (1998). Facilitation of a distributed electronic meeting. The Facilitator.

Van de Ven, A., \& Delbecq, A. (1974). The effectiveness of nominal, delphi and interacting group decision-making processes. Academy of Management Journal, 17, 605-621.

Vessey, I., \& Conger, S. (1993). Learning to specify information requirements. Journal of Management Information Systems, 10(2), 177-201.

White, S., Dittrich, J., \& Lang, J. (1980). The effects of group decision-making process and problem situation complexity on implementation attempts. Administrative Science Quarterly, 25, 428-440. 